\title{
Parkinson's Disease: Past, Present, and Future
}

Irwin J. Kopin, M.D.

\footnotetext{
The development of understanding of the pathophysiology ad modes of treatment of Parkinson's disease represents or of the triumphs of modern medicine, encompassing sute clinical observation, utilization of basic research podings regarding dopamine to develop the first rational arment of a degenerative disorder of the central wous system, and remains at the frontiers of murologic science. After characterization of the clinical ad pathologic features of Parkinson's disease, rational vetment awaited the discovery of the deficit in basal molia dopamine. On the basis of this observation and known biosynthetic pathways for dopamine mation, levodopa was introduced. Use of metabolic dibitors to prolong and potentiate the effects and avoid deleterious side effects of levodopa enhanced the 4 may of this neurotransmitter replacement strategy. The discovery and characterization of dopamine receptor types and the availability of selective dopamine ouists provided additional therapeutic approaches, but $\mathrm{nd}$ to address the underlying cause of the degenerative
}

process. The discovery and disclosure of the mechanisms of toxicity of the relatively selective nigrostriatal neurotoxin, 1-methyl-4-phenyl-1,2,5,6tetrahydropyridine (MPTP), triggered a resurgence of interest in etiological factors which might contribute to the development of parkinsonism and together with the report that inhibition of monoamine oxidase $B$ with deprenyl not only potentiated the effects of levodopa, but appeared to prolong the life of parkinsonian patients, resulted in a large-scale trial of drugs that might arrest the degenerative process. Furthermore, the MPTP primate model of Parkinson's disease has encouraged development of fetal mesencephalic and other tissue implant approaches to reversal of parkinsonism. Although much of this is still in the experimental stages, hopes are high that new and more effective therapies will be developed and that similar techniques might be applicable to a wide variety of neuropsychiatric disorders. [Neuropsychopharmacology 9:1-12, 1993]
Orr understanding of the causes and treatments of neumogic disorders is advancing at an increasingly rapid pre. Clinical neurology was born in the 19th century, nd the tenet that the symptoms of these diseases can bexplained by the attending brain pathology was first

\footnotetext{
from Intramural Research, National Institute of Neurological Dinders and Stroke, National Institutes of Health, Bethesda, uryand.

Mitress correspondence to: Irwin J. Kopin, M.D., Director, nural Research, NINDS, NIH, Building 10, Room 5N-214, mesdo, Maryland 20892.

Loived January 12, 1993; accepted February 7, 1993.

The DiMascio Lecture was presented at Tufts University School dinedicine, May 14, 1992.
}

established during the last third of that century. Yet progress was slow and often prodded only as a result of an accident or a serendipitous finding. During the last 30 years, however, the extraordinary explosion of knowledge of the neurochemical anatomy and molecular biology of the brain has revolutionized approaches to understanding the pathophysiology and treatment of some neurologic disorders. The story of progress in Parkinson's disease is particularly interesting because it illustrates so well the influence of events, sometimes tragic, as well as of scientific advances, that creates opportunities for new research efforts. It is my purpose to provide a historical perspective on Parkinson's disease and the events that have helped to propel our advances in understanding the disorder, to summarize 
our present state of knowledge, and to indicate the directions of future research.

\section{CHARACTERIZING PARKINSON'S DISEASE}

In a classic monograph, "An Essay on the Shaking Palsy," published over 175 years ago, the London physician, James Parkinson (1817), first described a "series" of six patients suffering from the movement disorder which came to bear his name. In an age when physical examinations had not yet been developed as a basis for diagnosis, his astute observations and graphic descriptions were sufficiently detailed to make the diagnosis inescapable. His characterization of its insidious onset, "that it rarely happens, that the patient can form any recollections of the precise period of its commencement," of "a slight sense of weakness, with a proneness to trembling in some particular part ... most commonly in one of the hands or arms" is still the best description of the earliest symptoms of Parkinson's disease. "Involuntary tremulous motion, with lessened muscular power, in parts not in action and even when supported: with a propensity to bend the trunk forward, and to pass from a walking to a running pace: the senses and the intellect being unimpaired" was his summary of the characteristic features of Paralysis Agitans. Its inexorable progression so that "the tremulous motion of the limbs occur during sleep and augment until they overwhelm the patient, and frequently with much agitation and alarm" and the ultimate helplessness, "the power of conveying the food to the mouth is at length so much impeded that he is obliged to consent to be fed by others," are strikingly portrayed.

During the remainder of the 19th century, additional features of the disease were described. As physical examinations became part of the study of patients, muscular rigidity and "cogwheeling" were noted by Trousseau (1867). The great French neuropathologist and neurologist, Jean-Martin Charcot, delineated the "pill rolling" parkinsonian tremor from other causes of tremor. He also noted that the patients were not weak, that some may have little or no tremor, and that absence of facial expression (masked facies) is a striking feature of the disorder (Charcot 1871; Goetz 1986). Charcot deemed inappropriate the terms "paralysis agitans" or "shaking palsy" and it was he who named the disorder Parkinson's disease.

Although the clinical characteristics were well described, pathological features of Parkinson's disease were not defined clearly until the 20th century and many, including Charcot, considered the disorder to be "functional," that is, a neuropsychiatric disorder. At the beginning of this century, Lewy (1913) first described the eosinophilic inclusion bodies that are characteristic of Parkinson's disease, although these are now recognized as occurring also in other degenerative dis- eases of the nervous system. Parkinson's disease was considered to be uncommon and was given little attention until its frequent occurrence as a sequel to von Economo's encephalitis lethargica (von Economo 1931), which reached epidemic proportions between 1918 and 1921. Study of the pathology of this disease led to the discovery by Tretiakoff (1919) that depigmentation of the substantia nigra is a consistent feature of parkinsonism. Loss of the neurons in this area then became recognized as characteristic of parkinsonism, whether the disorder was a result of viral infection, exposure to toxins, anoxia, or from unknown causes. Only 40 years ago, however, it was thought that "in view of widespread changes elsewhere in such cases it is difficult to relate the Parkinsonian syndrome to a lesion located in one situation" (Brain 1951).

\section{EMPIRICAL TREATMENT OF PARKINSON'S DISEASE}

The first pharmacotherapy for Parkinson's disease was introduced over a century ago by Ordenstein (1867). Belladonna alkaloids were administered as a meansfor controlling the annoying drooling described by Parkin. son, "the saliva fails of being directed to the back part of the faucies and hence is continually draining from the mouth." Unexpectedly, the drugs also improved the movement disorder. Although the beneficial effects are only modest $(20 \%$ to $30 \%$ ) and are obtained in only some $(60 \%$ to $80 \%)$ of the patients, they remained the mainstay of antiparkinsonian medication for over four generations. To obtain greater specificity in controlling rigidity and tremor and to reduce undesirable side effects, synthetic anticholinergic drugs, such as benztropine mesylate (Cogentin) and trihexylphenidyl (Artane), were introduced about 70 years later (Corbin 1949; Dorshay et al. 1949). It is generally accepted that these drugs act at muscarinic receptors in the striatum. presumably to balance excessive cholinergic activity, but even with current advances in our understanding of the striatal neurotransmitters and neuronal pathways, the exact mechanism of these drugs remains uncertain. Amphetamine had also been found to reduce rigidity (Solomon et al. 1937) and benadryl, an antihistamine with some anticholinergic effects, had been recommended (Budnitz 1948). Apomorphine, a drug that was best known as an emetic, serendipitously was found to be of use in parkinsonism (Schwab et al. 1951). With advances in our understanding of basal ganglia function, the basis for efficacy of these agents has become clearer.

\section{SURGICAL TREATMENT OF PARKINSON'S DISEASE}

The clinicalobservation that after a cerebrovascular ac cident, parkinsonian tremors become arrested on the 
side with hemiplegia led to the notion that surgical lesons of the brain might be useful in treating Parkinson's disease. However, early trials showed that lesions in the cortex or descending pyramidal tracts arrested temor only at the expense of paralysis. Other attempts at surgical treatments were also generally unsuccessful until Cooper (1961) accidentally discovered that ligation of the anterior choroidal artery abolished partinsonian tremor and rigidity without causing paralysis. Subsequent studies defined clinical criteria for accepunce for surgery and described the specific regions to betargeted to alleviate tremor or rigidity (Cooper 1965). The advent of levodopa treatment, however, eclipsed furtherexploration of the surgical approaches to treatment of Parkinson's disease. Recently, however, neumosurgical approaches have become increasingly promsing in having a role in the treatment of this movement disorder.

\section{DOPAMINE AND RATIONAL TREATMENT OF PARKINSON'S DISEASE}

The introduction of a rational treatment of Parkinson's disease and our current understanding of the pathophysiology of parkinsonian syndrome are attributable b the remarkable advances in the neurosciences that wve occurred during the last 35 years. In 1958, Carlsmand others (Carlsson et al. 1958; Bertler and Rosenon 1959) showed that dopamine was present in the hain, with highest concentrations in the striatum. They monstrated, in mice and in rabbits, that brain dopame is depleted by reserpine, and that administration d 3,4dihydroxyphenylalanine (DOPA) dramatically nerses reserpine-induced tranquilization, Parkinsonthe motor deficits, and ptosis. They showed also that prtreatment with a monoamine oxidase (MAO) inhibmpotentiated DOPA in reversing reserpine effects. Mese observations and the uneven distribution of atecholamines in brain suggested that these amines bution as neurotransmitters and that dopamine is invatued in control of motor activity. Several years later, greatly reduced (to about one tenth normal) concontrations of dopamine in the caudate, putamen, and mbstantia nigra of brains from parkinsonian patients wes reported (Ehringer and Hornykiewicz 1960). Siorly thereafter, by use of the newly developed Hofluorescence techniques to visualize catecholaines in neurons and their processes, various catecholmecell groups were identified and their projections monstrated (Anden et al. 1964; Lindvall and Bjorkand 1964). The previously unknown nigrostriatal dpamine-containing tract, with cell bodies in the subnia nigra pars compacta (SNc) and axonal projections to the striatum, explained the relationship bemen neuron loss in the SNc and dopamine depletion on the striatum.
These observations were seminal to understanding the pathophysiology of parkinsonian syndromes and encouraged attempts to pharmacologically replace the missing neurotransmitter. Because it was known that dopamine does not penetrate the blood-brain barrier but that DOPA, its amino acid precursor, reversed the behavioral effects of reserpine and elevated brain dopamine levels, it was apparent that this amino acid readily enters the brain and is decarboxylated (Fig. 1). Initial efforts at dopamine substitution with DOPA failed because of severe side effects, particularly nausea and vomiting. However, by gradually increasing the doses of DOPA and thereby avoiding or reducing adverse side effects, Cotziaset al. $(1967,1969)$ succeeded in administering high doses of DOPA and achieved remarkable symptomatic improvement. It appeared that Parkinson's disease was mostly a result of dopamine deficiency. Although other biochemical abnormalities, such as diminished levels of serotonin, norepinephrine, gamma-aminobutyric acid (GABA) and glutamate decarboxylase, have been found in brains of

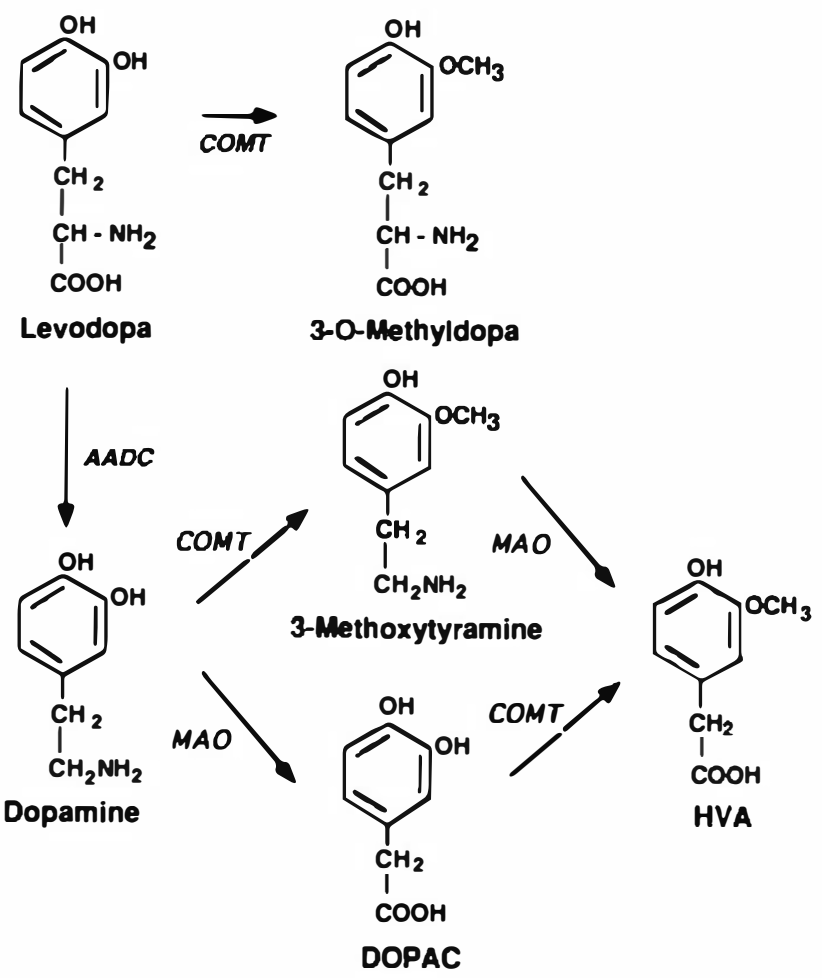

Figure 1. Formation and metabolisr. of dopamine. Dopamine is formed by the decarboxylation of levodopa mediated by the relatively nonspecific enzyme, AADC. Dopamine is readily decarboxylated by either subtype ( $A$ or $B$ ) of $M A O$ to form dehydroxyphenyl acetic acid (DOPAC). All three catechols (levodopa, dopamine, and DOPAC) are substrates for catechol-O-methyl transferase (COMT), forming 3-Omethyldopa, 3-methoxytyramine, and homovanillic acid, respectively. The pathway of formation of homovanillic acid and by deamination of methoxytyramine is minor. 
parkinsonian patients, the deficiencies are not as striking as the loss of dopamine. The physiologic isomer of DOPA, levodopa, was introduced and strategies were then focused on enhancing the efficacy of levodopa treatment.

Levodopa administered orally must pass from the lumen of the intestine into the hepatic and systemic circulations. Entry into the brain parenchyma requires transfer from blood through the endothelial cells lining the capillaries. Because considerable amounts of the decarboxylating enzyme, aromatic amino acid decarboxylase (AADC), are present in the intestinal wall, the liver, the kidneys, and the brain capillary endothelium, a good deal of the administered levodopa can be decarboxylated at these sites. Selective inhibition of extracerebral AADC was therefore explored as a means for enhancing levodopa efficacy. Two AADC inhibitors, carbidopa and benserazide, were found that could be administered in doses that affect only extracerebral AADC (including that of the brain capillaries) and were shown to be useful adjuncts to levodopa treatment (Papavasiliou et al. 1972; Pletscher 1973; Pinder et al. 1976). These drugs increase bioavailability of levodopa by enhancing levodopa absorption from the intestine, preventing its decarboxylation in the peripheral tissues and inactivating the brain capillary enzymatic barrier to levodopa. A similar strategy, using new inhibitors of catechol-O-methyl transferase, an enzyme involved in the metabolism of catechols (Fig. 1) is currently being explored as a means for potentiating dopamine and/or a levodopa sparing effect.

The antiparkinsonian effects of levodopa are generally stable and reasonably predictable for the first several years, but after some time, dyskinesias, fluctuations in efficacy ("on-off responses" and "wearing off"), freezing, mental changes, and loss of efficacy (requiring higher levodopa doses and inviting more side effects) emerge. Mechanisms that have been cited as contributing to these adverse effects include progression of the disease with diminished decarboxylation of levodopa to dopamine in brain, inability to regulate extracellular dopamine concentration by uptake into dopaminergic terminals, alterations in levodopa pharmacokinetics, and changes in dopamine receptor sensitivity and responsivity. On the basis of these hypotheses, during the 1970s and 1980s, several strategies were explored to restore levodopa efficacy and to avoid adverse effects. Dosages and times of levodopa administration were manipulated, slow release formulations or continuous intravenous infusions to stabilize levodopa plasma levels, and drug "holidays" to allow for normalization of dopamine receptors and potentiation were explored and prolongation of the effects of dopamine was attempted by inhibiting MAO. Although some improvements in symptomatic management were obtained, none of these modifications of levodopa therapy have been universally satisfactory. The common failures encountered with long-term levodopa treat. ment encouraged exploration of alternatives to levodopa.

Alleviation of dopamine deficiency by finding othes means of stimulating dopamine receptors seemed feasible. It was recognized that the parkinsonian side effects of some antipsychotic drugs might be related to blockade of dopamine receptors and reasoned that stimulation of these receptors would reverse parkinsonian symptoms.

\section{DOPAMINE RECEPTOR AGONISTS}

Dopamine receptor agonists and antagonists were first discovered because of their ability to evoke or block be. havioral or endocrine effects associated with dopamine. Some ergot derivatives, for example, bromocryptine, were found to inhibit prolactin secretion, whereas drugs that depleted dopamine (reserpine) or had antipsychotic effects (chlorpromazine) enhanced prolactin secretion. When it appeared that dopamine agonists might be useful in treating Parkinson's disease, several ergot derivatives were tested and found to be effective. The actions of these drugs (e.g., bromocriptine, lisuride, pergolide) are not identical, and they do not mimic doparinine precisely, presumably because they each in. teract differently, from dopamine and from each other, with dopamine receptor subtypes.

\section{Dopamine Receptor Subtypes}

Nearly 15 years ago, dopamine receptors were classified into two subtypes (Kebabian and Caine 1979); stimulation of $D_{1}$ receptors activated adenylcyclase and thereby enhanced cyclic adenosine monophosphate (AMP) production, whereas stimulation of $\mathrm{D}_{2}$ receptors failed to affect adenylcyclase or even diminished cyclic AMP formation. Subsequent demonstration of two types of binding sites for radioactively labeled dopa mine agonists and antagonists confirmed the division of dopamine receptors into at least two categories. The demonstration in brain of anatomically distinct bind. ing sites for radioactively labeled dopamine agonists and antagonists further supported the division of dopa mine receptors into at least two categories (Young and Penney 1989). The distinction between the two subtypes of dopamine receptors also made possible the charac. terization of dopamine agonists with regard to their ac. tions at these receptors subtypes. Dopamine $D_{2}$ recep. tor stimulating properties appear to be important for antiparkinsonian effects; however, there are significant $D_{1}-D_{2}$ synergistic interactions so that drugs that have some degree of $D_{1}$ agonist activity have some advartages. Within the last 3 years, not only have the $D_{1}$ and $\mathrm{D}_{2}$ receptor subtypes been cloned (Bunzow et al. 1988; Dearry et al. 1990; Zhou et al. 1990; Monsma et al. 1990, but three additional dopamine receptor subtypes have 
been characterized (Sokoloff et al. 1990; Van Toi et al., 1991; Sunahara et al. 1991). The $\mathrm{D}_{3}$ and $\mathrm{D}_{4}$ receptors, resemble the $D_{2}$ subtype, whereas the $D_{5}$ resembles the $D_{1}$. Five different alleles of the $D_{4}$ receptor have been identified in humans (Van Toi et al. 1992), but the significance of these differences has yet to be established. It is possible that one or more dopamine agonists which act directly on dopamine receptor subtypes, and therefore independently of degenerated dopaminergic neurons, might provide advantages in the control of symptoms in parkinsonian patients who can no longer respond to the indirectly acting levodopa.

\section{PATHWAYS THROUGH THE BASAL GANGLIA}

Tobetter understand how dopamine may affect motor control, it is necessary to define the role of the basal anglia in modulating cortical motor function. The basal anglia are components of parallel cortical-subcorticalwrical circuits that are important in the control of movements. The connections between the cortex, basal ganetia, substantia nigra, and subthalamic and thalamic mocleihave been traced, and compartmental organization and biochemical characteristics of the striatum described (Parent 1990; Alexander and Crutcher 1990; Graybiel 1990; Gerfen 1991, 1992). The basic circuits and their neurotransmitters/modulators are shown in Figwe 2. Glutaminergic excitatory neurons that project from the cortex arborize and form synapses with dendittes on the medium spiny GABAergic neurons, which constitute over $90 \%$ of the neurons in the striatum. The triatal inhibitory neurons innervate the inner layer of the globus pallidus $(\mathrm{GPi})$ in primates (or the endopeduncular nucleus in rodents) and the neurons of the substantia nigra reticulata (SNr). The target neumons of this "striatonigral" projection are also GABAerfic and send inhibitory exons to the thalamus where rey innervate excitatory glutaminergic neurons which project to the cortex. These four neurons (corticostria$\omega$ striato-pallidal or -nigral, pallido- or nigro-thalamic, nd thalamocortical) constitute direct cortical-subcoriral-cortical circuits (Fig. 2); the two inhibitory synapses mount for disinhibition and activation of descending otor neurons. There is another, parallel GABAergic projection from the striatum to the external layer of the tobus pallidus (GPe). The GABAergic neurons from the GPe innervate glutaminergic excitatory neurons in the subthalamic nucleus. The subthalamic neurons inwervate GABAerigc neurons in the GPi and thus proide an alternative, indirect, five-neuron corticalmbortical-cortical circuit (Fig. 2); the three inhibitory gnapses have a net inhibitory effect, inhibiting disinWition. Smooth and efficient motor control requires mordination and balance of the output of these opposmpathways attained by modulatory mechanisms that re only beginning to be understood in terms of the ormization and special characteristics of subpopulations

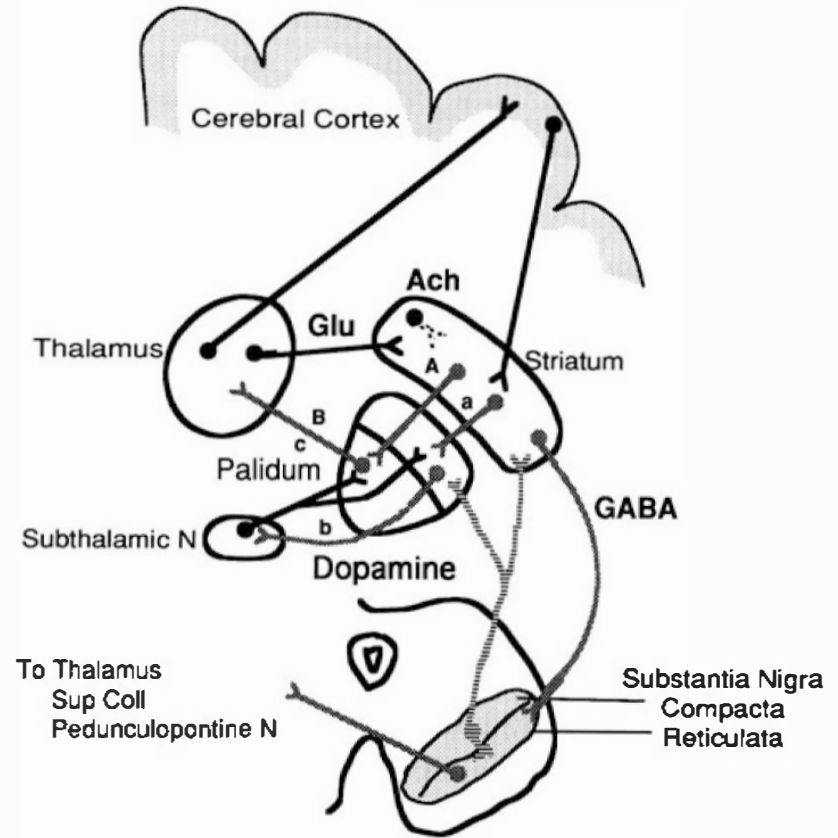

Figure 2. Diagrammatic representation of the cortical-basal ganglia-thalamo-cortical neuronal circuits and their modulation by intrastriatal cholinergic and nigrostriatal dopaminergic neurons (see text).

of the neurons and the neuromodulators that regulate the output of these pathways.

Acetylcholine and dopamine are among the best characterized of these modulators. A network of "striasomes" or "patches," which makes up $10 \%$ to $20 \%$ of the striatal volume, in contrast to the matrix, is characterized by low density of acetylcholine esterase (AChE). A relatively small number of large aspiny striatal neurons that contain choline acetyltransferase presumably are cholinergic. Both the dendrites and the axonal arborizations of theseneurons reach a relatively large surrounding volume and presumably have a role in modulating striatal function. It is likely that the beneficial antiparkinsonian effects of anticholinergic agents are due to actions at cholinergic synapses innervated by these neurons. Dopaminergic neurons project from the SNc to the striatum where they form a dense network of synaptic contacts. Dopamine is released at many sites and dopamine receptors are present on the axons, dendrites, and somata of neurons which constitute these circuits. Thus, there is ample opportunity for dopaminergic modulation of nerve activity through these pathways. There are also important functional interactions between $D_{1}$ and $D_{2}$ receptors. The complexity of interconnections via neuronal networks, feedback circuits, and $D_{1}-D_{2}$ receptors on the same cell defies simple analysis, but it is evident that the net effects of dopamine deficiency produce parkinsonian symptoms. Release of dopamine by amphetamine, the action of apomorphine on dopamine recep- 
tors, and the action of amantidine on dopamine disposition probably explain their antiparkinsonian affects.

During the last 20 years the neuroanatomic and pharmacologic basis for symptomatic treatment of parkinsonian syndromes by dopamine and dopamine agonists has become better understood. Although initially effective, levodopa has well-recognized limitations; improvements in therapy are still required to control symptoms after levodopa failure. Prevention or arrest of the degenerative process, not addressed by symptomatic treatments, is receiving increasing attention.

\section{DISCOVERY OF A TOXIN THAT CAUSES PARKINSONISM}

Approximately 10 years ago, a neurotoxin that was destined to change the focus of Parkinson's disease research was first recognized. The first reported case of parkinsonism resulting from 1-methyl-4-phenyl-1,2,3,6tetrahydropyridine (MPTP) was that of a 23-year-old student who was referred to the National Institutes of Health (NIH) because of a history of multiple drug abuse and the rapid development of severe parkinsonism (Davis et al. 1979). The young man had synthesized on several occasions alphaprodine, an analogue of demerol, which he had used intravenously, often with cocaine. Carelessness in synthesis and purification resulted in production of a side reaction product, MPTP, which was a major component of the impure demerol analogue. After several daily self-administered doses of the impure narcotic, he was found mute and immobile. The initial diagnosis of catatonic schizophrenia resulted in hospitalization in a mental institution, but his striking rigidity subsequently led to a suspicion of severe parkinsonism; this was confirmed by successful treatment with L-DOPA/carbidopa and the patient was referred to NIH. After admission, the history of drug synthesis and use was elicited and the components of the drug mixture discovered. The motor deficits were indistinguishable from Parkinson's disease, and his cerebrospinal fluid levels of homovanillic acid, the major metabolite of dopamine, were markedly lower than normal, consistent with the clinical diagnosis. After discharge, he continued abusing drugs and was found dead from an overdose of cocaine and demerol. Examination of the brain showed severe degeneration of the nigrostriatal neurons, neurochemical evidence of dopaminergic deficit, and a single eosinophilic body in the region of the substantia nigra.

Administration to rats, rabbits, or guinea pigs of MPTP, its precursor or alphaprodine, alone or in combination, failed to produce a toxic motor deficit (Chiueh et al. 1984). Several years after the initial case, there surfaced in California a cluster of patients with toxic par- kinsonism due to MPTP (Langston et al. 1983), also apparently as a result of an attempted illicit synthesis of alphaprodine.

With the knowledge of the resistance of rodents to toxicity of MPTP, the compound was now administered to rhesus monkeys, and these animals were found to be vulnerable to the toxin (Burns et al. 1983). Daily intravenous administration of several relatively small doses of MPTP was followed by the rapid development over a few days of stooped posture, marked brady. cardia, tremor, and rigidity. Initially, there were marked decreases in the cerebrospinal fluid levels of homovanitlic acid, 3-methoxy-4-hydroxyphenylglycol, and 5-hydroxyindoleacetic acid, the major metabolites of dopa. mine, norepinephrine, and serotonin, respectively, but only the levels of homovanillic acid remained low after 1 month. All of the motor deficits were reversed temporarily by the administration of L-DOPA. When the brains of these animals were examined, there was at. most complete destruction of the neurons in the substantia nigra and marked depletion of dopamine in the striatum. Other brain regions with dopaminergic of noradrenergic neurons were relatively unaffected by the toxin. Thus MPTP appeared to specifically target dopaminergic neurons of the nigrostriatal pathway. A similar parkinsonian syndrome in squirrel monkeys (Langston et al. 1984), marmosets (Jenner et al. 1984), and other primate species was found to be caused by MPTP. Although rats, guinea pigs, rabbits, and gerbils appear to resist MPTP toxicity, when administered repeatedly in high doses, mice were found to be vulnerable to the toxin; but in mice, both noradrenergic neurons and dopaminergic neurons throughout the brain as well as the nigrostriatal neurons are affected (Hallman et al. 1984; Heikkila et al. 1984). The mouse, however, has been widely used to examine the mecha. nisms of MPTP toxicity. The discovery that 1-methyl. 4-phenylpyridinium $\left(\mathrm{MPP}^{+}\right)$is formed and retained in the brains of monkeys treated with MPTP (Markey et al. 1984) suggested that biotransformation (Fig. 3) of the administered compound to its oxidized metabolite was important for toxicity. High concentrations of $\mathrm{MPP}^{+}$found in regions of brain which escape extensive damage indicate that dopaminergic neurons of the $\mathrm{SNc}$ are peculiarly vulnerable to the toxic effects of $\mathrm{MPP}^{+}$. Conversion of MPTP to MPP+ is mediated by MAO type B. Rat brain mitochondria were found to oxidize MPTP to MPP ${ }^{+}$, and the oxidation was found to be prevented by deprenyl, a specific MAO-B inhibitor, but not by clorgyline, a specific MAO-A inhibitor (Chiba et al. 1984). In monkeys, pretreatment with pargyline, a nonspecific MAO inhibitor, or deprenyl prevents both the accumulation of $\mathrm{MPP}^{+}$and the toxic effects of MPTP (Markey et al. 1984; Langston et al. 1984b; Cohen et al. 1985). In mice also, pretreatment with inhibjtors of MAO prevents striatal dopamine depletion 


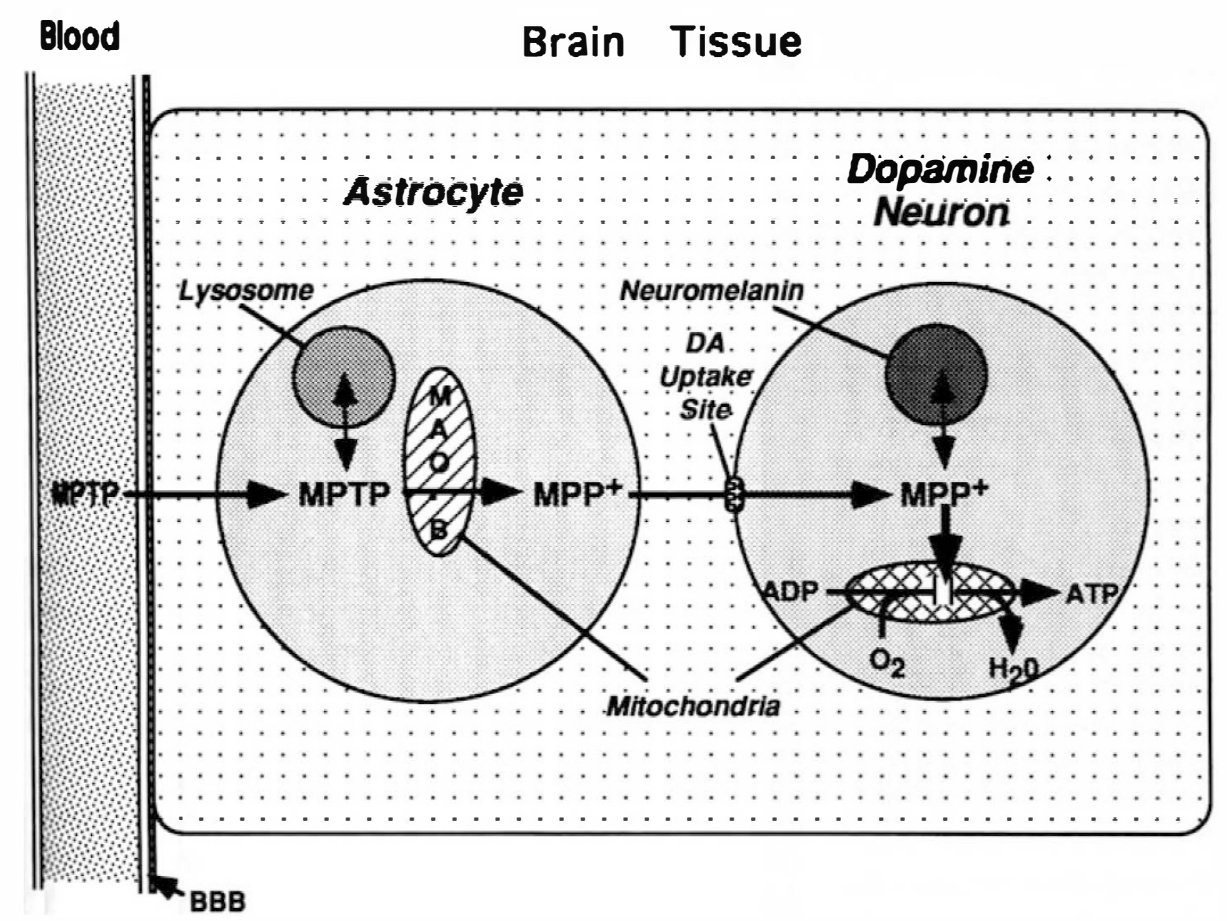

Figure 3. Mechanisms involved in the neurotoxicity of MPTP. MPTP readily penetrates the blood brain barrier and is immediately captured into acidic organelles (lysosomes) in astrocytes from which it enters the cytoplasm to reach mitochondrial MAO (type B) that oxidizes it to $\mathrm{MPP}^{+}$. The MPP ${ }^{+}$leaches in the extracellular fluid from which it is actively transported by the catecholamine transporters into the neurons. The changed amine is accumulated in neuromelanin-containing organelles and is further concentrated into mitochondria where it blocks mitochondrial respiration and causes depletion of adenosine triphosphate. In vulnerable neurons, this accumulation leads to cell death (see text).
(Heikkila et al. 1984b). A number of studies have shown that MAO-B is localized to astrocytes and serotonergic neurons, whereas $\mathrm{MAO}-\mathrm{A}$ is present in catecholaminergicneurons, so that MAO-B-mediated MPTP oxidation to MPP + does not take place in the catecholaminecontaining neurons. Formation of $\mathrm{MPP}^{+}$is necessary but not sufficient for manifestation of the toxic effects m animals. Although, in vitro, $\mathrm{MPP}+$ is toxic to a varitry of noncatecholaminergic cells, in vivo, MPTP toxic dfects are limited to catecholaminergic neurons. The specificity for catecholaminergic neurons may be accounted for by the observation that $\mathrm{MPP}^{+}$is a subtrate for the catecholamine transporters (Fig. 3). Synytosomes prepared from rat striatum (Javitch and Snyder, 1984) or cortex (Javitch et al. 1985) accumulate H-MPP ${ }^{+}$, but not ${ }^{3} \mathrm{H}-\mathrm{MPTP}$. The uptake of ${ }^{3} \mathrm{H}-\mathrm{MPP}{ }^{+}$ striatal synaptosomes is blocked by inhibitors of dopamine uptake, and with potencies which are well orrelated with blockade of dopamine uptake. Also, the potencies of several drugs in blocking cortical synaptosome ${ }^{3} \mathrm{H}$-norepinephrine uptake are similar to their potencies in blocking ${ }^{3} \mathrm{H}-\mathrm{MPP}+$ uptake. In mice, those drugs that block norepinephrine transport protect noradrenergic neurons against the toxic effects of WPT; those drugs that block uptake of dopamine prond dopaminergic neurons. Perhaps because of the long persistence of $\mathrm{MPP}^{+}$in primate brain, it has been more diffcult to demonstrate a protective effect of dopamine tronsport blockers on prevention of MPTP toxicity in primates. Studies with MPTP analogues have supported the view that neurotoxicity is dependent on the ability of a protoxin to penetrate the blood-brain barrier, to be converted by MAO (usually, but not necessarily, type B), and to be concentrated by the amine transporters in the target neurons.

The molecular basis of toxicity has been studied mostly in cultured cells. Initially, it was speculated that the toxicity of $\mathrm{MPP}^{+}$was, like a structurally similar toxic herbicide, paraquat (1-1'-dimethyl-4,4'-bipyridinum), a result of free radical cycling with generation of excess superoxide ions $\left(\mathrm{O}_{2}^{-}\right)$. Normally superoxide dismutase converts superoxide ions to hydrogen peroxide and water, and catalase decomposes the hydrogen peroxidase to water and oxygen. If excess superoxide and hydrogen peroxide accumulate, particularly in the presence of bivalent metal ions, such as, $\mathrm{Fe}^{++}$, the highly reactive hydroxyl free radical $(\mathrm{OH} \cdot)$ is formed. Glutathione, a-tocopherol, ascorbic acid, and other soluble reducing substances provide protection against oxidative damage, but if these are overloaded, cell components essential for life (membrane lipids, deoxyribonucleic acid, DNA, cofactors, etc.) are disrupted; metabolic and transport processes fail and death follows. Although some indirect evidence for the involvement of free radicals in $\mathrm{MPP}^{+}$toxicity has been obtained, it is highly unlikely that redox cycling of MPP+ is involved; however, free radical formation by other mechanisms has not been excluded. 
The currently favored hypothesis for molecular basis for $\mathrm{MPP}^{+}$toxicity is inhibition of mitochondrial respiration (Singer and Ramsay 1990; Kopin 1992). In addition to its accumulation by amine transporters in dopaminergic neurons, $\mathrm{MPP}^{+}$is further concentrated into mitochondria where it inhibits the electron transport at complex I. This interference with energy metabolism and the possible enhanced generation of free radicals as a result of partial reduction of oxygen is believed to cause the cell damage and to disrupt vital processes essential for cell survival.

The attention attracted by the discovery of MPTP and its mechanisms of toxicity has had an enormous influence on the directions of research on Parkinson's disease. Recognition and understanding of the mechanisms of toxicity of MPTP provided clues as to the pathogenesis of Parkinson's disease, and the availability of so faithful an animal model of human parkinsonism has opened opportunities for exploration of new therapies and approaches to preventing or arresting the degenerative process.

\section{FOCUS ON PATHOGENESIS AND NEUROPROTECTION}

Although the primary cause of Parkinson's disease is unknown, a number of clues have suggested that a combination of hereditary and environmental factors may affect survival of dopaminergic neurons.

\section{Environmental Neurotoxins}

The occurrence of MPTP-induced parkinsonism in at least one chemist who had synthesized large quantities of the compound (Burns et al. 1985) proved that it was possible that sporadic cases of Parkinson's disease could result from exposure to an environmental toxin. Extensive searches for environmental or endogenous toxins have yielded provocative epidemiologic evidence in support of a neurotoxin in the environment (Tanner and Langston 1990), but no such toxins have been identified.

\section{Oxidative Stress}

Exploration of the processes involved in MPTP toxicity rekindled interest in previously proposed mechanisms of nigrostriatal degeneration. Oxidation of catecholamines, whether by autoxidation of the catechol moieties to hydroquinones or quinones, or by enzymatic oxidative deamination results in the formation of reactive oxygen species (superoxide anion, hydroxyl radical, and hydrogen peroxide). Transitional metals such as manganese and iron catalyze the transfer of electrons during the partial reduction of oxygen, and the coincidence of high dopamine and iron contents in the SNc has encouraged hypotheses linking free radical formation with Parkinson's disease (Graham 1984; Cohen 1985). Considerable evidence has been accumulated to support the view that oxidative stress and free radical formation catalyzed by iron might play an important role in the pathogenesis of Parkinson's disease (Jenner 1991). When dopamine release is enhanced, levels of oxidized glutathione increase; this index of oxidative stress attending dopamine release can be prevented by pretreatment with an inhibitor of MAO-B (Cohen and Spina 1989). Increased lipid peroxidation in the substantia nigra of parkinsonian patients (Dexter et al. 1989), supports the notion that free radicals have damaged the dopaminergic neurons in the nigrostriatal pathway. Particular vulnerability of the SNc to oxidative stress may result from deficiencies in protective mechanisms. Levels of superoxide dismutase are reported to be elevated, whereas levels of glutathione and glutathione peroxidase have been reported to be abnormally low in the substantia nigra of Parkinson's disease patients (Saggu et al. 1989; Perry and Yong 1986). Conversion of superoxide and hydrogen peroxide to the highly reactive hydroxyl ion (Haber-Weiss reaction) is normally slow, but in the presence of iron, the reaction is rapid. Post-mortem levels of iron, particularly ferric ion, are increased in the substantia nigra of parkinsonian patients (Sofic et al. 1991; Dexter et al. 1991), but the iron appears to be deposited in astrocytes, macrophages, reactive glia, and nonpigmented neurons (Hirsch et al. 1991). Thus, although there appears to be increased iron deposited in the substantia nigra of parkinsonian patients, it is unclear if this is a result of the neuronal degeneration or due to an abnormality in iron metabolism.

Selectivity of MPTP and of the degenerative process in Parkinson's disease for melanin-containing neurons suggests that conditions that predispose to melanin formation may be responsible for vulnerability of these cells to the degenerative process, or that neuromelanin plays a role by producing free radicals or by storing a neurotoxin that is slowly released and has a more prolonged toxic effect on the cells in which it is stored. Neuromelanin is a complex redox polymerthat contains free radicals; it has also been proposed that neuromelanin-iron interactions might account for the vulnerability of pigmented neurons to oxidative stress (Ben-Shachar et al. 1991).

\section{Mitochondrial Abnormalities}

Deficiencies in mitochondrial electron transport similar to those caused by $\mathrm{MPP}^{+}$have been reported in 
platelets and in muscle as well as in substantia nigra of parkinsonian patients, but it is claimed that the mitochondrial defect is confined to the substantia nigra Mann et al. 1992). Such mitochondrial abnormalities, however, are not necessarily primary etiological factors; they might be secondary to other metabolic deficits. Free radicals formed during reversible inhibition of complex lappear to inhibit irreversibly electron transport at complex I (Cleeter et al. 1992). Thus, excess free radicals produced from any source might be responsible for the defciency in complex I activity reported in Parkinson's disease.

\section{Neuroprotective Agents to Arrest the Degenerative Process}

Selective inhibition of MAO-B with deprenyl was introduced to explore its use in the management of fluctuating responses to levodopa/carbidopa and in diminshing the "on-off" effects, as well as to prolong and potentiate the efficacy of levodopatreatment. Birkmayer etal. (1985), however, reported that patients who had received deprenyl along with levodopa therapy appeared to live longer than those treated with levodopa done. This report, the observation that MPTP toxicity an be prevented by inhibition of MAO-B with deprenyl, and the newly emerging hypotheses regarding the role doxidative stress, provided the rationale for prospective, randomized, double-blind studies to examine the possibility that deprenyl alone or in combination with in antioxidant, tocophenol, might retard the progresson of the degenerative process of Parkinson's disease.

Deprenyl (selegiline) and/or tocopherol were administered to previously untreated parkinsonian patients and deprenyl, with or without tocopherol, was found to significantly delay the onset of disability sefficient to warrant initiation of levodopa therapy (The Parkinson Study Group 1989). Although the findings were dramatic, whether they were the result of sympwmatic improvement due to potentiation of endogenous dopamine (by any of several potential mechanisms) or a really neuroprotective effect is the subject $d$ considerable controversy (see Olanow and Caine 1922), particularly since treatment with deprenyl did not produce any significant biochemical changes to subsantiate a free radical scavenging effect (Baronti et al. (992).

In monkeys, systemic administration of MK-801, scompetitive antagonist for the N-methyl-D-aspartate meptor, has been reported to prevent the development $d$ the parkinsonian syndrome induced by MPTP, although the brain levels of MPP+ were higher than in monkeys receiving MPTP alone (Zuddas et al. 1992). Hexcitotoxins play a significant role in the degenera- tive process in Parkinson's disease, then another approach to neuroprotection may become important.

\section{NEURAL TISSUE IMPLANTS IN PARKINSON'S DISEASE}

During the last decade, neural grafting has emerged as an experimental means for repairing damaged neuronal systems in the central nervous system of humans. Initial studies were performed in rats with lesions produced by 6-hydroxydopamine. More recently, monkeys treated systemically with MPTP or made hemiparkinsonian by intracarotid injection of the neurotoxin have provided a primate model of Parkinson's disease. In rats, developing dopamine brain cells, obtained from the substantia nigra region of embryonic cadavers, implanted intothe striatum were found to reinnervate part of the previously denervated striatum and to restore dopamine turnover and release to near-normal levels. In both rats and monkeys, fetal nigral grafts reverse, at least in part, parkinsonian symptoms (Lindvall 1991). Although autologous adrenal medullary grafts in patients with Parkinson's disease had been reported to be beneficial, initial enthusiasm for this procedure has waned in the light of further experience. Survival of the grafted tissue is poor and the marginal benefits are outweighed by the significant morbidity.

Human fetal mesencephalic tissue implanted into the striatum has been reported to survive in the human parkinsonian brain and produce therapeutically valuable functional effects. Most recently, two patients were reported to have shown a gradual and significant amelioration of parkinsonian symptoms starting at 6 and 12 weeks after grafting and reaching peak improvement within 4 to 5 months after which they remained stable during the 1-year follow-up period (Lindvall et al. 1992). Clinical improvement, observed as a reduction of the time spent in the "off" phase and the number of daily "off periods." There was a lessening of bradykinesia and rigidity, mainly, but not solely, on the side contralateral to the graft. Assessment by positron emission tomography with 6-L- $\left[{ }^{18} \mathrm{~F}\right]$ fluorodopa provided evidence that dopamine synthesis and storage in the grafted area had been restored and taken with animal experimental data, suggest that neural transplantation can be developed into an effective therapy in Parkinson's disease.

Studies in several laboratories have established that implantation of fetal dopamine-containing tissue into the caudate nucleus of MPTP-parkinsonian monkeys leads to behavioral recovery. Similar recovery can be obtained, however, with fetal nervous tissue that does not contain dopamine-producing cells (Bankiewicz et al. 1991). In that study, implant-induced improvement 
was stable for up to 6 months and post-mortem examination revealed sprouted dopaminergic fibers. The fibers appeared to be derived from dopamine neurons surviving in regions less affect by MPTP, suggesting that implant-induced and trophic factor-mediated dopaminergic sprouting by the host brain neurons could play a role in the behavioral recovery and clinical improvement seen in parkinsonian patients after brain implants.

It is clear that further work is necessary to establish the mechanisms of the effects and to optimize the transplantation procedure. It is possible that cells genetically engineered to produce dopamine or neurotrophic factors will prove to be of use in replacing dopamine, restoring dopaminergic innervation or arresting progression of the degenerative process.

\section{Summary}

The saga of research on Parkinson's disease begins with astute clinical observation and includes a pandemic of encephalitis and toxin-induced parkinsonism in young chemists and drug abusers. These tragic events provided incentives and clues for progress in understanding parkinsonism from all causes. The remarkable advances in the neurosciences have contributed enormously to elucidating the pathophysiology of the disorder and have provided the basis for the introduction of levodopa, the first rational treatment of a disorder of the central nervous system. Newer understandings of the role of growth and of neurotrophic factors, of oxidative stress, and of molecular biology, as well as use of brain tissue implants as means for treatment of Parkinson's disease, are pacing the advances in the exciting search for means of preventing and arresting the progression as well as providing symptomatic treatment of degenerative diseases of the nervous system.

\section{REFERENCES}

Alexander GE, Crutcher MD (1990): Functional architecture of basal ganglia circuits: Neural substrates of parallel processing. Trends Neurosci 13:266-271

Anden NE, Carlsson A, Dahlstrom A, Fuxe K, Hillarp N-A, Karlsson K (1964): Demonstration and mapping of nigroneostriatal dopamine neurons. Life Sci 3:523-530

Bankiewicz KS, Plunkett RJ, Jacobowitz DM, Kopin IJ, Oldfield EH (1991): Fetal nondopaminergic neural implants in parkinsonian primates. Histochemical and behavioral studies. J Neurosurg 74:97-104

Baronti F, Davis TL, Boldry RC, Mouradian MM, Chase TN (1992): Deprenyl effects on levodopa pharmacodynamics, mood, and free radical scavenging. Neurology 42:541-544

Ben-Schachar D, Riederer P, Youdim MB (1991): Iron-melanin interaction and lipid peroxidation: Implications for Parkinson's disease. J Neurochem 57:1609-1614
Bertler A, Rosengren E (1959): Occurrence and distribution of catecholamines in brain. Acta Physiol Scand 47:350-361

Brain WR (1951): Diseases of the Nervous System 4th Ed. Lon. don, Oxford University Press, 456

Budnitz J (1948): Use of benadryl in Parkinson's disease. N Engl J Med 238:874.

Burns RS, Chiueh CC, Markey SP, Ebert MH, Jacobowitz DM, Kopin IJ (1983): A primate model of parkinsonism: Selec. tive destruction of dopaminergic neurons in the pars compacta of the substantia nigra by $\mathrm{N}$-methyl-4-phenyl. 1,2,3,6-tetrahydropyridine. Proc Natl Acad Sci USA 80:4546-4550

Burns RS, LeWitt PA, Ebert MH, Pakkenberg H, Kopin I] (1985): The clinical syndrome of striatal dopamine deficiency. Parkinsonism induced by 1-methyl-4-phenyl. 1,2,3,6-tetrahydropyridine (MPTP). N Engl J Med 312:1418-1421

Bunzow JR, Van Tol HH, Grandy DK, Albert P, Salon J, Christie M, Machida CA, NeveKA, Civelli O (1988): Cloning and expression of a rat $\mathrm{D}_{2}$ dopamine receptor $\mathrm{CDNA}$. Nature 336:783-787

Carlsson A, Lindquist M, Magnusson T, Waldeck B (1958): On the presence of 3 hydroxytyramine in brain. Science 127:471-472.

Charcot JM (1871): Lecons sur les Malades de Systeme Nerveux: Faltes a la Salpetriere. Paris, Delahaye et Lacros. mier, pp 155-188

Chiueh CC, Markey SP, Burns RS, Johannessen JN, Jacobowitz DM, Kopin IJ (1984): Neurochemical and behavioral effects of 1-methyl-4-phenyl-1,2,3,6-tetrahydropyridine (MPTP) in rat, guinea pig, and monkey. Psychopharmacol Bull 29:548-553

Cohen G, Spina MB (1989): Deprenyl suppresses the oxidant stress associated with increased dopamine turnover. Ann Neurol 26:689-690

Cohen G, Pasik P, Cohen B, Leist A, Mytilineou C, Yahr M (1985): Pargyline and deprenyl prevent the neurotoxicity of 1-methyl-4-phenyl-1,2,3,6-tetrahydropyridine (MPTP) in monkeys. Eur J Pharmacol 106:209-210

Cooper IS (1961): Parkinsonism, Its Medical and Surgical Therapy. Springfield, IL, Charles C. Thomas

Cooper IS (1965): Surgical treatment of Parkinson's disease Annu Rev Med 16:309-330

Corbin KB (1949): Trihexyphenyl: Evaluation of a new agent in the treatment of Parkinson's disease. JAMA 141: 373-381

Cotzias GC, Van Woert MH, Schiffer LM (1967): Aromatic amino acids and modification of parkinsonism. N Eng J Med 276:374-378

Cotzias GC, Papavasiliou PS, Gellene R (1969): Modification of parkinsonism - chronic treatment with L-dopa. NEng J Med 280:337-345

Davis GC, Williams AC, Markey SP, Ebert MH, Caine ED Beichert CM, Kopin IJ (1979): Chronic parkinsonism ser. ondary to intravenous injection of meperidine analogues. Psychiatry Res 1:249-254

Dearry A, Gingrich JA, Falardeau P, Fremeau RT Jr, Bates MD, Caron MG (1990): Molecular cloning and expres sion of the gene for a human $\mathrm{D}_{1}$ dopamine receptor. $\mathrm{Na}$ ture 347:72-76 
Dexter DT, Carter CJ, Wells FR, Javoy-Agid F, Agid Y, Lees A, Jenner P, Marsden CD (1989): Basal lipid peroxidation in substantia nigra is increased in Parkinson's disease. J Neurochem 52:381-389

Dexter DT, Carayon A, Javoy-Agid F, Agid Y, Wells FR, Daniel SE, Lees AJ, Jenner P, Marsden CD (1991): Alterations in the levels of iron, ferritin and other trace metals in Parkinson's disease and other neurodegenerative diseases affecting the basal ganglia. Brain 114:1953-1975

Dorshay LJ, Constable K (1949): Active therapy for parkinsonism. JAMA 140:1317

Ehringer H, Hornykiewicz O (1960): Verteilung von noradrenalin und dopamin (3-hydroxytramin) in gerhirn desmenshenen und ihr verhalten bei erkrankungen des extrapyramidalen systems. Klin Wochenschr 38:12361239

Cerfen CR (1991): The neostriatalmosaic: Multiple levels of compartmental organization. Trends Neurosci 14:133-139

Cerfen CR (1992): The neostriatalmosaic: Multiple levels of compartmental organization in the basal ganglia. Annu Rev Neurosci 15:285-320

Coetz CG (1986). Charcot on Parkinson's disease. Movement Disord 1:27-32

Graybiel AM (1990): Neurotransmitters and neuromodulators in the basal ganglia. Trends Neurosci 13:244-253

Hallman H, Olson L, Jonsson G (1984): Neurotoxicity of the meperidine analogue $\mathrm{N}$-methyl-4-phenyl-1,2,3,6tetrahydropyridine on brain catecholamine neurons in the mouse. Eur J Pharmacol 97:133-136

Heikkila RE, Hess A, Duvoisin RC (1984a): Dopaminergic neurotoxicity of 1-methyl-4-phenyl-1,2,5,6-tetrahydropyridine in mice. Science 224:1451-1453

Hezkila RE, Manzino L, Cabbat FS, Duvoisin RC (1984b): Protection against the dopaminergic neurotoxicity of 1-methyl-4-phenyl-1,2,5,6-tetrahydropyridine by monoamine oxidase inhibitors. Nature 311:467-469

Hirsch EC, Brandel JP, Galle P, Javoy-Agid F, Agid Y (1991): Iron and aluminum increase in the substantia nigra of patients with Parkinson's disease: An x-ray microanalysis. J Neurochem 56:446-451

Fitch JA, Snyder SH (1984): Uptake of $\mathrm{MPP}^{+}$by dopamine neurons explains selectivity of parkinsonism-inducing neurotoxin, MPTP. Eur J Pharmacol 106:455-456

Ivitch JA, D'Amato RJ, Strittmatter SM, Snyder SH (1985): Parkinsonism-inducing neurotoxin, $\mathrm{N}$-methyl-4-phenyl1,2,3,6-tetrahydropyridine: Uptake of the metabolite $\mathrm{N}$-methyl-4-phenylpyridine by dopamine neurons explains selective toxicity. Proc Natl Acad Sci USA 82:2173-2177

Anner P (1991): Oxidative stress as a cause of Parkinson's disease. Acta Neurol Scand Suppl 136:6-15

Inner P, Rupniak NM, Rose S, Kelly E, Kilpatrick G, Lees A, Markey SP, Johannessen JN, Chiueh CC, Burns RS, Herkenham MA (1984): Intraneuronal generation of a pyridinium metabolite may cause drug-induced parkinsonism. Nature 311:464-467

Robian JW, Caine DB (1979): Multiple receptors for dopamine. Nature 277:93-96

Iopin Il (1992): Features of the dopaminergic neurotoxin MPTP. Ann NY Acad Sci 648:96-104
Langston JW, Ballard P, Tetrud JW, Irwin I (1983): Chronic parkinsonism in humans due to a product of meperidineanalog synthesis. Science 219:979-980

Langston JW, Forno LS, Rebert CS, Irwin I (1984a): Selective nigral toxicity after systemic administration of 1-methyl4-phenyl-1,2,5,6-tetrahydropyrine (MPTP) in the squirrel monkey. Brain Res 292:390-394

Langston JW, Irwin I, Langston EB, Forno LS (1984b): Pargyline prevents MPTP-induced parkinsonism in primates. Science 225:1480-1482

Lewy FH (1913): Zue pathologischen Anatomie der Parlysis agitans. Deutsche $Z$ Nervenheilkunde 50:50-55

Lindvall O (1991): Transplants in Parkinson's disease. Eur Neurol 31 (Suppl 1):17-27

Lindvall O, Bjorklund A (1974): The organization of the ascending catecholamine neuron systems in the rat brain as revealed by the glyoxalic and fluorescence method. Acta Physiol Scand Suppl 412:1-48

Lindvall $\mathrm{O}$, Widner $\mathrm{H}$, Rehncrona $\mathrm{S}$, Brundin $\mathrm{P}$, Odin $\mathrm{P}$, Gustavii B, Frackowiak R, Leenders KL, Sawle G, Rothwell JC, et al (1992): Transplantation of fetal dopamine neurons in Parkinson's disease: One-year clinical and neurophysiological observations in two patients with putaminal implants. Ann Neurol 31:155-165

Marsden CD (1984): 1-Methyl-4-phenyl-1,2,3,6-tetrahydropyridine-induced parkinsonism in the common marmoset. Neuroscience 50:85-90

Monsma FJ Jr, Mahan LC, McVittie LD, Gerfen CR, Sibley DR (1990): Molecular cloning and expression of a D1 dopamine receptor linked to adenylyl cyclase activation. Proc Natl Acad Sci USA 87:6723-6727

Olanow CW, Calne D (1992): Does selegiline monotherapy in Parkinson's disease act by symptomatic or protective mechanisms? Neurology 42:13-26

Ordenstein I (1867): Sur la paralysie agitante Martinet. Paris

Papavasiliou PS, Cotzias GC, Duby SE, Steck AJ, Fehling C, Bell MA (1972): Levodopa in parkinsonism: Potentiation of central effects with a peripheral inhibitor. N Engl J Med 286:8-14

Parent A (1990): Extrinsic connections of the basal ganglia. Trends Neuroscience 13:254-258

Perry TL, Yong VW (1986): Idiopathic Parkinson's disease, progressive supranuclear palsy and glutathione metabolism in the substantia nigra of patients. Neurosci Lett 67:269-274

Parkinson J (1817): An Essay on the Shaking Palsy. London: Sherwood, Neely, and Jones

Pinder RM, Brogden RN, Sawyer PR, Speight TM, Avery GS (1976): Levodopa and decarboxylase inhibitors: A review of their clinical pharmacology and use in the treatment of parkinsonism. Drugs 11:329-377

Pletscher A (1973): Effect of inhibitors of extracerebral decarboxylase on levodopa metabolism. Adv Neurol 3:49-58

Saggu H, Cooksey J, Dexter D, Wells FR, Lees A, Jenner P, Marsden CD (1989): A selective increase in particulate superoxide dismutase activity in parkinsonian substantia nigra. J Neurochem 153:692-697

Schwab RS, Amador LV, Lettvin JY (1951): Apomorphine in Parkinson's disease. Trans Am Neurol Assoc 76:251 
Sofic E, Paulus W, Jellinger K, Riederer P, Youdim MB (1991): Selective increase of iron in substantia nigra zona compacta of parkinsonian brains. J Neurochem 156:978-982

Sokoloff P, Giros B, Martres MP, Bouthenet ML, Schwartz JC (1990): Molecular cloning and characterization of a novel dopamine receptor $\left(D_{3}\right)$ as a target for neuroleptics. Nature 347:146-151

Solomon P, Mitchell RS, Prinzmetal M (1937): The use of benzedrine sulfate in post-encephalitic Parkinson's disease. Am Med Assoc J 108:1765-1770

Sunahara RK, Guan HC, O'Dowd BF, Seeman P, Laurier LG, Ng G, George SR, Torchia J, Van Tol HH, Niznik HB (1991): Cloning of the gene for a human dopamine $D_{5}$ receptor with higher affinity for dopamine than $D_{1}$. Nature 350:614-619

Tretiakoff C (1919): Contribution a l'etude de l'anatomie pathologiqaue du Locus Niger de Soemmering. Thesis, Paris

Young AB, Penney JB (1989): Receptors in the basal ganglia:
Chap 4 in Drugs for the treatment of Parkinson's disease. ed. Donald B. Caine. Springer-Verlag, Berlin, pp 149-163

Van Tol HH, Bunzow JR, Guan HC, Sunahara RK, Seeman P, Niznik HB, Civelli O (1991): Cloning of the gene for a human dopamine $D_{4}$ receptor with high affinity for the antipsychotic clozapine. Nature 350:610-614

VanTolHH, Wu CM, GuanH-C, Ohara K, Bunzow JR, Civelli O, Kennedy J, Seeman P, Niznik HB, Jovanovik V (1992): Multiple dopamine $\mathrm{D}_{4}$ receptor variants in the human population. Nature 358:149-152

von Economo C (1931): Encephalitis Lethargica, Its Sequelae and Treatment. London, Oxford University Press, $p 113$

Zhou QY, Grandy DK, Thambi L, Kushner JA, Van Tol HH, Cone R, Pribnow D, Salon J, Bunzow JR, Civelli O (1990): Cloning and expression of human and rat $\mathrm{D}_{1}$ dopamine receptors. Nature 347:76-80

Zuddas A, Oberto G, Vaglini F, Fascetti F, Fornai F, Corsin GU (1992): MK-801 prevents 1-methyl-4-phenyl-1,2,3,6tetrahydropyridine-induced parkinsonism in primates J Neurochem 59:733-739 